
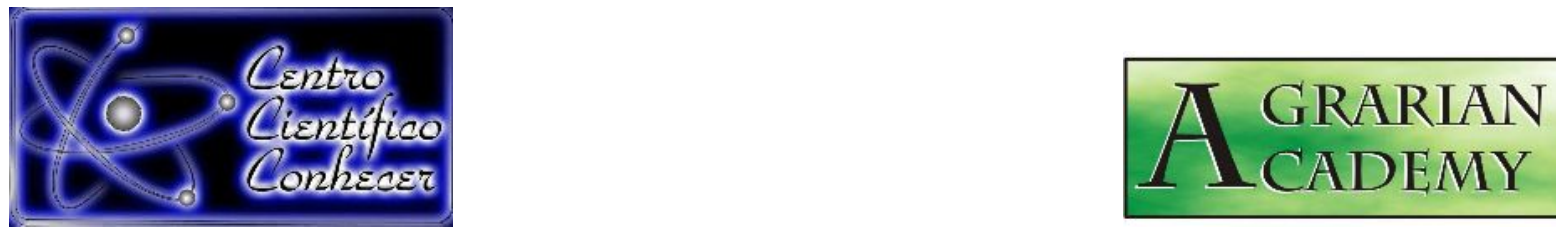

\title{
DESENVOLVIMENTO INICIAL DA SOJA SOB DIFERENTES DOSES DE ADUBAÇÃO POTÁSSICA
}

\author{
Nerton da Penha Filho ${ }^{1 *}$, Salenilza Pires de Almeida ${ }^{2}$,
}

Tainá Macêdo dos Santos ${ }^{2}$, Wíctor Állyson Dias Rodrigues ${ }^{2}$, Felipe Thomaz da Camara $^{3}$

1 Graduando em Engenharia Agronômica da Universidade Federal do Cariri

(nerton.filho96@hotmail.com), Crato-Brasil;

2 Graduando em Engenharia Agronômica, Universidade Federal do Cariri;

3 Dr., Prof. Adjunto CCAB, Universidade Federal do Cariri.

Recebido em: 14/07/2018 - Aprovado em: 28/07/2018 - Publicado em: 31/07/2018

DOI: 10.18677/Agrarian_Academy_2018a18

A soja consolidou-se a cultura agrícola de maior importância para o Brasil e pode dar origem a diversos produtos. O potássio é o segundo nutriente mais importante para a soja, ficando atrás do nitrogênio. Sua deficiência nos solos pode causar danos severos na soja. Assim, objetivou-se avaliar o efeito de doses de potássio sobre o desenvolvimento inicial da soja. O experimento foi conduzido no Centro de Ciências Agrárias e da Biodiversidade da Universidade Federal do Cariri. O delineamento experimental foi em blocos casualizados, com quatro tratamentos e seis repetições, totalizando 24 parcelas. Os tratamentos consistiram em quatro doses de potássio $(0$, 25,50 e $100 \%$ do recomendado). As variáveis analisadas foram: altura da planta (Altura), comprimento da raíz (CR), número de folhas (NF) e massa da parte aérea (MA), da raíz (MR) e total (MT) de cinco plantas. Os dados foram submetidos à análise de variância e de regressão utilizando-se o programa estatístico SISVAR 5.3. As variáveis: Altura, CR, NF, MA, MR e MT não apresentaram significância pelo teste de Tukey a $5 \%$ de probabilidade para o fator adubo. Entretanto, as variáveis MA e MR apresentaram resposta quadrática significativa a $10 \%$ de probabilidade, apresentando a massa máxima $(44,37 \mathrm{~g}) \operatorname{com} 58,5 \%$ e $(8,24 \mathrm{~g})$ com $50,75 \%$ da dose recomendada para o nutriente potássio, respectivamente. As doses de adubação que apresentaram o melhor resultado foram entre 50 e $60 \%$. A Altura teve comportamento linear, com acréscimos à medida que elevaram-se as doses de potássio.

PALAVRAS-CHAVE: Crescimento, Manejo, nutrição. 


\title{
INITIAL DEVELOPMENT OF SOYBEAN UNDER DIFFERENT DOSES OF POTASSIUM FERTILIZATION
}

\begin{abstract}
Soybean consolidates the greatest agricultural culture to Brazil and originates a sort of products. Potassium is the second nutrient more important to soybean, being behind nitrogen. Its deficiency in soil may cause severe damage to soybean. Thereby, it was objected the effect of doses of potassium under the initial development of soybean. The experiment was conducted at the Center of Agricultural Science and Biodiversity in the Federal University of Cariri. The experimental design was in randomized blocks, with four treatments and six repetitions, totalizing 24 plots. The treatments consisted in four potassium doses $(0,25,50$ e $100 \%$ of the recommended). The analyzed variables were plant height (Altura), root length (CR), number of leaves (NF) and mass of aerial part (MA), root (MR) and total (MT) of 5 plants. Data were submitted to variance and regression analysis utilizing the statistic program SISVAR 5.3. the variables Altura, CR, NF, MA, MR e MT didn't present significance by Tukey test at $5 \%$ of probability to fertilizer factor. However, the variable MA and MR presented significative quadratic answer at $10 \%$ of probability, presenting the highest mass $(44,37 \mathrm{~g})$ with $58,5 \%$ and $(8,4 \mathrm{~g})$ with $50,75 \%$ of the recommended dose to the potassium nutrient, respectively. The fertilizing doses that presented the best result were between 50 and $60 \%$. Plant height had a linear behavior, with additions as the potassium doses were increased.
\end{abstract}

KEYWORDS: Growth, management, nutrition.

\section{INTRODUÇÃO}

A soja, cultura originada na China, se consolidou como a cultura agrícola de maior importância para o Brasil. Na safra 2016/2017 foi o segundo maior produtor, com 114,075 milhões de toneladas, e o maior exportador mundial, com 58,4 milhões de toneladas (KORBER et al., 2017; CONAB, 2018). A região Centro-Oeste apresenta a maior influência nessa cultura entre as regiões brasileiras, com $46,1 \%$ da área plantada e 46,8\% da produção nacional (LEAL et al., 2015).

Essa cultura apresenta a facilidade de que sua matéria prima pode dar origem a diversos produtos, como, por exemplo, o uso do farelo na alimentação animal e o óleo no consumo humano (MANTOVANI et al., 2017). No Nordeste, o papel de destaque é realizado pelo estado da Bahia que apresenta a maior área plantada da região (PETTER et al., 2014).

Esse estado está inserido nas áreas responsáveis pela maior expansão da fronteira agrícola brasileira, conhecida como MATOPIBA. Estas áreas de cerrado apresentam alto potencial de crescimento na produção e produtividade (LEITE et al., 2017). Nesse último quesito é indispensável o uso de adubação equilibrada para que a cultura possa apresentar o máximo potencial (RODRIGUES et al., 2015).

Encontrando-se em baixas concentrações em áreas de cerrado, o potássio (K) é o segundo nutriente mais importante para a soja, ficando atrás do nitrogênio que é fixado através da simbiose com as bactérias do gênero Bradyrhizobium. Nesse sentido, é necessário o aumento da concentração do $\mathrm{K}$ nesses solos atráves da adubação mineral (JÚLIO et al., 2016; BRACCINI et al., 2016).

O K está diretamente relacionado às altas produtividades da soja, atuando nas atividades celulares, promovendo tanto a abertura e fechamento estomático e 
controle osmótico dos tecidos, como também atuando nas atividades enzimáticas (DOMINGOS et al., 2015; MANTOVANI et al., 2017).

A deficiência de $\mathrm{K}$ nos solos pode causar danos severos na soja. Os principais sintomas de deficiência são a clorose internervural, seguida de necrose no ápice e nas bordas das folhas mais velhas, além de causar a redução na fotossíntese, dimuindo a qualidade das sementes (DOMINGOS et al., 2015).

O fornecimento adequado promove ganhos de rendimentos significativos durante o final do ciclo, como no número de vagens por planta, porcentagem de vagens com grãos e aumento da nodulação. Promove maior qualidade na semente, pois diminui a incidência de doenças sobre a cultura e promove a tolerância aos fatores abióticos (TRIGOLO et al., 2015; MANTOVANI et al., 2017). Com base nisso, o objetivo desse trabalho foi avaliar o efeito de diferentes doses de potássio sobre o desenvolvimento inicial da cultura da soja.

\section{MATERIAL E MÉTODOS}

O experimento foi conduzido no período de 25 de outubro a 25 de novembro de 2017 no Centro de Ciências Agrárias e da Biodiversidade (CCAB) da Universidade Federal do Cariri (UFCA), localizada no município de Crato, Ceará, com as coordenadas geodésicas $7^{\circ} 14^{\prime} 49^{\prime \prime S}$, 39²2'05"W e 414 metros de altitude. O clima da região é tropical úmido com inverno seco e estação chuvosa de novembro a abril (verão) e estação seca de maio a outubro (inverno), que corresponde à classificação climática Aw de Köeppen. As precipitações geralmente são superiores a $750 \mathrm{~mm}$ anuais nas regiões de clima Aw', sendo encontrado esse clima no litoral e serras do Ceará (EMBRAPA, 2016).

O solo foi classificado como Argissolo Vermelho Amarelo, de textura arenosa, conforme a classificação de solos de média intensidade da FUNCEME (2012). A constituição química na camada de $0-20 \mathrm{~cm}$ foi: $\mathrm{pH}$ 1:2,5 H2O: 4,9; P melich-1: 6,3 $\mathrm{mg} \mathrm{dm}{ }^{-3}$; K: 1,28 mmolc dm${ }^{-3}$; Ca: 7,9 mmolc dm${ }^{-3}$; $\mathrm{Mg}: 5,6 \mathrm{mmolc} \mathrm{dm}^{-3}$; CTC: 33,8 mmolc $\mathrm{dm}^{-3}$ e V (\%): $45 \%$.

O delineamento experimental utilizado foi em blocos casualizados, com quatro tratamentos e seis repetições, totalizando 24 parcelas experimentais. Os tratamentos consistiram em quatro doses de potássio $\left(\mathrm{K}_{2} \mathrm{O}\right)$ aplicados na semeadura da soja, com valores de 0, 25, 50 e 100\% da dose recomendada para a cultura. Cada parcela experimental ocupou uma área de $4,5 \mathrm{~m}^{2}$, correspondente a três fileiras de soja com $3 \mathrm{~m}$ de comprimento e espaçadas a $0,45 \mathrm{~m}$ entre si. Foi considerada como parcela útil a fileira central com um metro de comprimento, sendo este o local da coleta das plantas para análise.

No dia 05 de setembro de 2017 foi realizada a calagem para elevar a saturação por bases para $70 \%$. Em seguida foram realizadas duas gradagens para incorporação do calcário. No dia 11 de setembro foi realizada a instalação do sistema de irrigação por micro aspersão, com turno de rega diário para suprir a demanda da cultura, com lâmina diária de $6 \mathrm{~mm}$. A área permaneceu em pousio por um mês e 20 dias para esperar a correção da acidez do solo.

No dia 25 de outubro foi feita uma gradagem leve na área para o preparo do solo. Em seguida, foram feitos os sulcos espaçados a $0,45 \mathrm{~m}$, com $0,1 \mathrm{~m}$ de profundidade. Foram depositados os adubos de plantio, conforme a dose recomendada para a cultura da soja. Evidencia-se que para esta operação foram utilizados adubos simples em função de não existir fórmula comercial compatível.

Desta forma, foram utilizados na adubação de fundação, para todas as parcelas, $100 \mathrm{~kg} \mathrm{ha}^{-1}$ de sulfato de amônio $\left(20 \mathrm{~kg} \mathrm{ha}^{-1}\right.$ de N) e $389 \mathrm{~kg} \mathrm{ha}^{-1}$ de 
superfosfato simples $\left(70 \mathrm{~kg} \mathrm{ha}^{-1}\right.$ de $\left.\mathrm{P}_{2} \mathrm{O}_{5}\right)$. As quantidades de potássio foram as únicas que sofreram variações de acordo com os tratamentos, sendo a dose recomendada (100\%) a quantidade de $67 \mathrm{~kg} \mathrm{ha}^{-1}$ de cloreto de potássio $\left(40 \mathrm{~kg} \mathrm{ha}^{-1}\right.$ de $\mathrm{K}_{2} \mathrm{O}$ ), para os demais tratamentos, as doses usadas foram variações proporcionais desta dose recomendada

A cultivar da soja utilizada nesse trabalho foi a M8349 IPRO, a mesma apresenta um elevado potencial produtivo, com ampla adaptação geográfica, alta estabilidade e excelente arquitetura de planta. $O$ plantio foi realizado com espaçamento de $8 \mathrm{~cm}$ entre sementes, totalizando uma densidade de 277.778 sementes ha-1.

As plantas foram colhidas da parcela útil aos 30 DAS para a análise do desenvolvimento inicial das plantas, sendo avaliadas as variáveis: altura da planta, comprimento da raíz, número de folhas, massa da parte aérea, da raiz e total. $A$ altura das plantas foi medida da superfície do solo até o ápice do ramo principal com uso de trena. O comprimento da raiz foi medido com trena, considerando-se a raiz principal. A massa da parte aérea e das raízes foi medida em balança semianalítica de precisão, com três casas decimais para gramas. A massa total foi a soma da massa de raízes e da parte aérea. Os dados foram tabulados e submetidos à análise de variância e à análise de regressão para seleção do maior expoente significativo, utilizando-se o programa estatístico SISVAR 5.3 (FERREIRA, 2010).

\section{RESULTADOS E DISCUSSÃO}

$\mathrm{Na}$ tabela 1, pode-se observar, através da análise de variância dos dados encontrados neste trabalho, que as variáveis: Altura, Comprimento da Raíz (CR) e o Número de Folhas por planta (NF) não apresentaram resultados significativos para a adubação potássica, a $5 \%$ de probabilidade pelo teste de Tukey.

Em relação ao coeficiente de variação (CV), Pimentel Gomes (2009) elaborou uma classificação para esse fator em experimentos em campo. Para as duas primeiras variáveis (Altura e CR) o CV está dentro da média (10-20), enquanto o NF pode ser considerado alto, mesmo estando próximo ao valor médio. Resultados semelhantes foram encontrados por Bárbaro-Torneli et al. (2018), estudando algumas variáveis agronômicas da soja, explicaram que os CVs com esses níveis de variação são aceitáveis para a cultura da soja.

Estudando o efeito da presença de duas variedades de sorgo sobre o crescimento inicial da raíz e da parte aérea da soja, Olibone et al. (2006) não encontraram efeitos significativos para as características altura e comprimento da raíz, entretanto as médias foram maiores para a variedade que depositou maior quantidade de $\mathrm{K}$ no solo. Tavares et al. (2013), avaliando o efeito de diferentes doses e fontes de potássio sobre a qualidade fisiológica e o rendimento de sementes, também não encontraram efeito significativo para as variáveis Altura e CR.

Já Pereira et al. (2016), avaliando doses de potássio, com ou sem enxofre, na cultura da soja, encontram resposta quadrática significativa para a variável Altura e NF e explicam que a principal função desse nutriente na planta é como ativador enzimático e regulador da pressão osmótica, ou seja, atuando diretamente na formação das folhas. 
TABELA 1. Síntese da análise de variância e do teste de médias para altura da planta (Altura), o comprimento da raíz (CR) e o número de folhas por planta (NF).

\begin{tabular}{ccccc}
\cline { 3 - 5 } Fontes de Variação & G.L. & \multicolumn{3}{c}{ Quadrados Médios } \\
\cline { 3 - 5 } & 5 & $2,31^{\mathrm{NS}}$ & $\mathrm{CR}$ & $\mathrm{NF}$ \\
\hline Bloco & 3 & $2,25^{\mathrm{NS}}$ & $9,57^{\mathrm{NS}}$ & $22,89^{\mathrm{NS}}$ \\
Adubo $(\mathrm{A})$ & 2,01 & 13,35 & $10,53^{\mathrm{NS}}$ \\
Resíduo & 15 & 10,19 & 18,41 & 20,03 \\
\hline CV $(\%)$ & - & $13,94 \mathrm{~cm}$ & $19,84 \mathrm{~cm}$ & 19,19
\end{tabular}

NS: não significativo; CV(\%): coeficiente de variação.

Petter et al. (2014), testando os efeitos da época e doses de aplicação de adubação potássica na cultura da soja, obtiveram resposta significativa para a variável comprimento da plântula, gerando como resultado uma equação linear. Esse resultado corrobora com o encontrado no presente trabalho, que apesar de não ter significância segundo o teste $F$, quando submetido à análise de regressão, obteve-se resposta linear significativa a $17 \%$ de probabilidade, como pode ser visto no gráfico 1, com o aumento nas doses de potássio, ocorreu acréscimo na altura da planta.

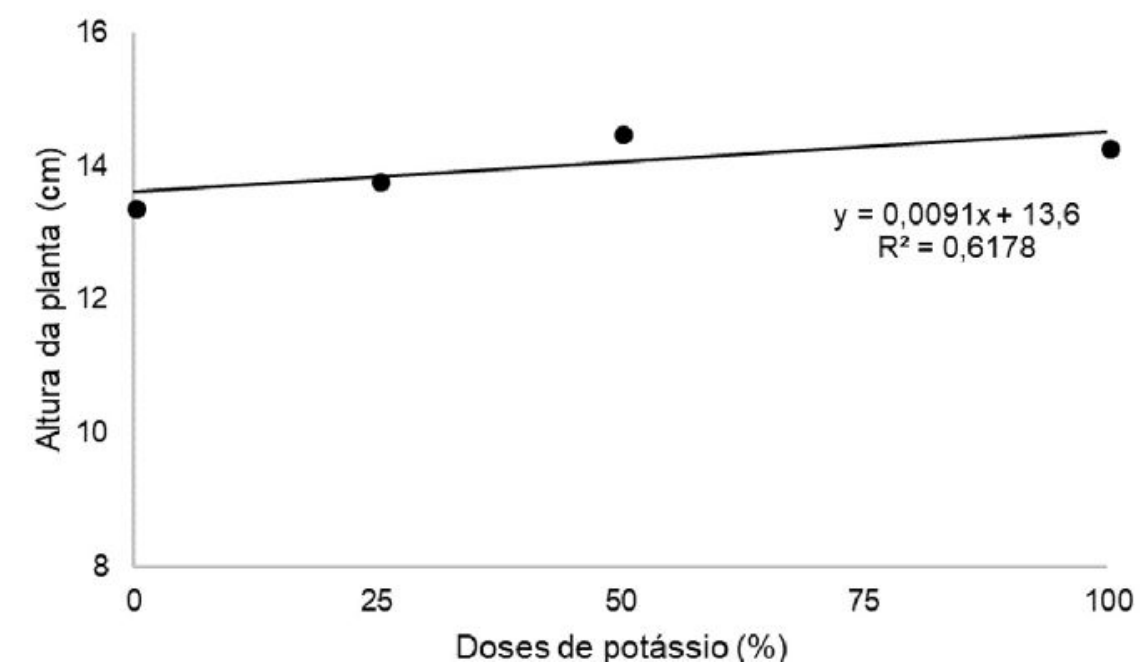

FIGURA 1. Análise de resgressão da altura da planta em função das doses de potássio.

Já Pazuch et al. (2017), não encontraram efeito significativo ao final do ciclo quando avaliaram formas e épocas de aplicação da adubação potássica sobre os rendimentos da cultura. Nesse mesmo trabalho foi explicado que a altura da planta é uma variável que interfere diretamente sobre as outras características produtivas, como números de nós produtivos, altura de inserção da primeira vagem e até no direcionamento dos fotoassimilados.

$\mathrm{Na}$ tabela 2, as variáveis massa da parte aérea de cinco plantas (MA), massa da raíz de cinco plantas (MR) e massa total de cinco plantas (MT) não apresentaram valores significativos no teste de Tukey a $5 \%$ de probabilidade para o fator adubo. 
TABELA 2. Síntese da análise de variância e do teste de médias para a massa da parte aérea de 5 plantas (MA), massa da raíz de 5 plantas (MR) e massa total de 5 plantas (MT).

\begin{tabular}{ccccc} 
Fontes de Variação & G.L. & \multicolumn{3}{c}{ Quadrados Médios } \\
\cline { 2 - 5 } & & MA & MR & MT \\
\hline Bloco & 5 & $112^{\mathrm{NS}}$ & $5,19^{\mathrm{NS}}$ & $144,55^{\mathrm{NS}}$ \\
Adubo $(\mathrm{A})$ & 3 & $135,9^{\mathrm{NS}}$ & $3,85^{\mathrm{NS}}$ & $182,49^{\mathrm{NS}}$ \\
Resíduo & 15 & 129 & 3,60 & 159,37 \\
\hline CV $(\%)$ & - & 29,22 & 25,48 & 27,25 \\
\hline Média Geral & - & $38,87 \mathrm{~g}$ & $7,44 \mathrm{~g}$ & $46,32 \mathrm{~g}$ \\
\hline${ }^{* *}:$ significativo (P<0,01); *: significativo & $(\mathrm{P}<0,05) ;$ & $\mathrm{NS}:$ não & significativo; CV\%: \\
coeficiente de variação. & &
\end{tabular}

No que diz respeito ao $\mathrm{CV}$, os valores são considerados altos, porém aceitáveis, segundo Pimentel Gomes (2009). O ambiente, pragas e doenças interferem nos resultados, visto que o presente trabalho foi conduzido inteiramente no campo.

No gráfico 2, a variável MA apresentou resposta quadrática significativa a 10\% de probabilidade, apresentando a massa máxima $(44,37 \mathrm{~g}) \mathrm{com} 58,5 \%$ da dose recomendada para o nutriente potássio. Olibone et al. (2006), encontraram maior resposta para a massa seca da parte aérea quando utilizaram como adubo o sorgode-Guiné que, em comparação com 0 sorgo forrageiro, proporciona maior concentração de $\mathrm{K}_{2} \mathrm{O}$ ao solo, ficando prontamente disponível para ser absorvido pela soja, entretanto não apresentou significância.

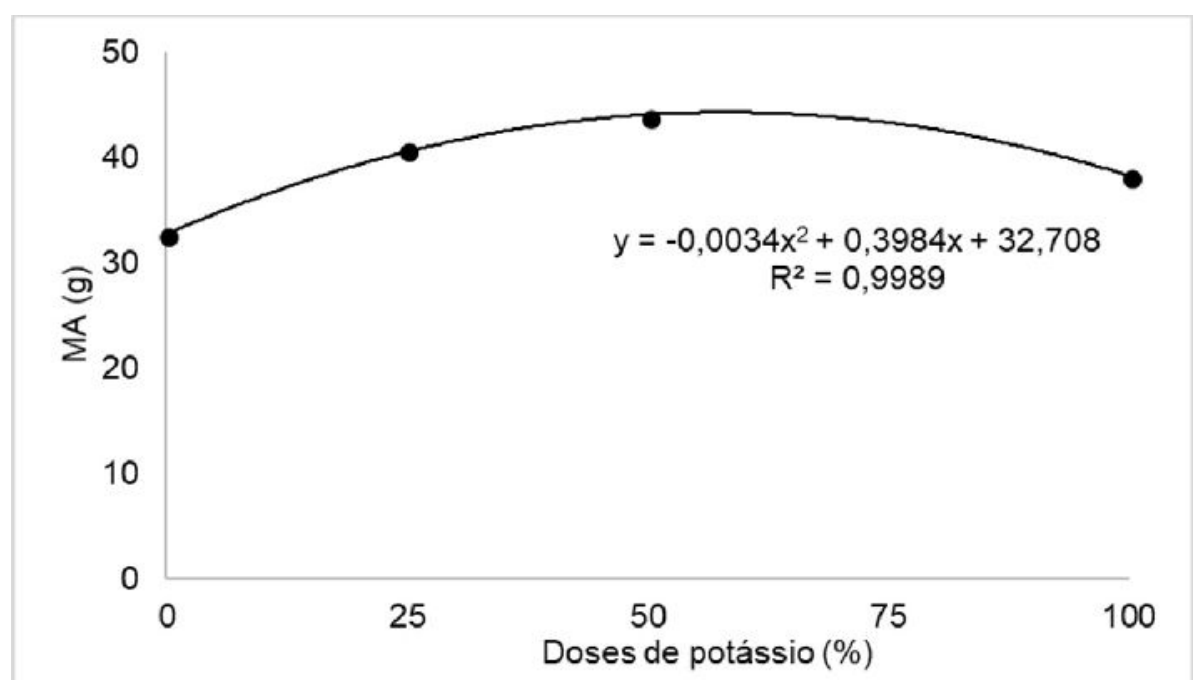

FIGURA 2. Análise de resgressão da massa da parte aérea de cinco plantas em função das doses de potássio.

Resultados similares com o desse trabalho foram observados por Pereira et al. (2016), que encontraram resposta quadrática significativa para essa variável, obtendo o melhor resultado com a dose aproximada de $100 \mathrm{~kg}^{-h^{-1}} \mathrm{de}_{2} \mathrm{O}$ em solo com fertilidade corrigida. Esses resultados podem ser explicados pelo fato do $\mathrm{K}$ apresentar influência sobre alguns processos metábolicos da planta, como 
fotossíntese, translocação de fotoassimilados, regulador osmótico e no fechamento e abertura estomática (JÚLIO et al., 2016).

No gráfico 3, a variável MR apresentou resposta quadrática significativa a 10\% de significância, apresentando resposta máxima $(8,24 \mathrm{~g})$ com $50,75 \%$ da dose da adubação recomendada. Kawavata et al. (2017), avaliando o efeito de doses crescentes de duas fontes de potássio sobre o milho, também encontraram respostas quadráticas, observando redução na massa seca das raízes de acordo com o aumento das doses do adubo. Nesse trabalho foi explicado que a diminuição do conteúdo radicular pode ter sido causada pela alta concentração de sais provenientes do adubo.

Outros autores ao trabalharem com soja também constataram essa afirmação em seus experiementos, como Venturoso et al. (2009), que estudando o desempenho agronômico de duas cultivares de soja submetidas a 4 doses de potássio, concluíram que o Cloreto de Potássio apresenta alto índice salino $(116,3)$, alterando a arquitetura da raíz, além de prejudicar a germinação das plântulas se aplicados valores acima de $50 \mathrm{~kg} \cdot \mathrm{ha}^{-1}$.

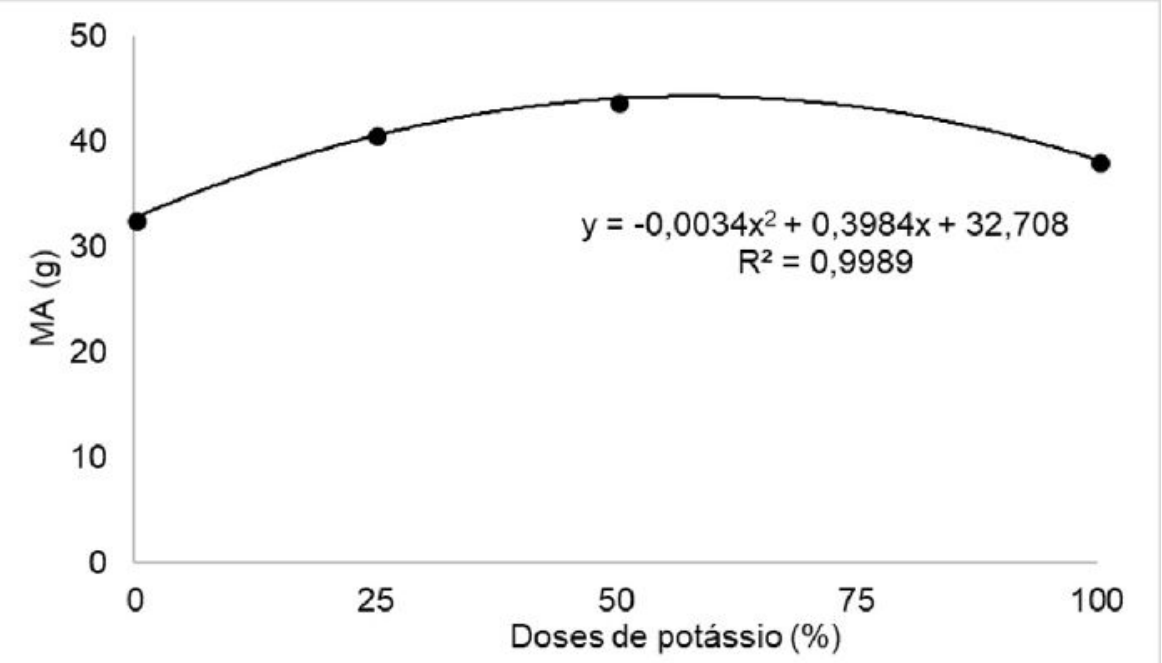

FIGURA 3. Análise de resgressão da massa da raíz de cinco plantas em função das doses de potássio.

\section{CONCLUSÕES}

As doses de potássio não apresentaram diferenças significativas a $5 \%$ de probabilidade pela análise de variância para as variáveis estudadas. Entretanto, apresentam respostas significativas a 10\% (Massa da parte aérea e das raízes) e 17\% (Altura) de significância para a análise de regressão.

Para a massa da parte aérea e de raízes e, consequentemente, massa total, as doses de $\mathrm{K}_{2} \mathrm{O}$ entre 50 e $60 \%$ apresentaram os melhores resultados, enquanto a altura da planta teve comportamento linear, com acréscimos na altura à medida que elevaram-se as doses de potássio.

\section{AGRADECIMENTOS}

À Universidade Federal do Cariri e ao Programa de Educação Tutorial - PET, pela bolsa concedida e pelo fornecimento dos materiais necessários para a realização dessa pesquisa. 


\section{REFERÊNCIAS}

BÁRBARO-TORNELI, L. M.; FINOTO, E. L.; TOKUDA, F. S; MEDEIROS, C. N. F.; GASPARINI, A. C.; BORGES, W. L. B.; et al.,; Influência de modos de aplicação da co-inoculação no desempenho agronômico de soja. Nucleus. Edição Especial, 2018. DOI: 10.3738/1982.2278.3008. Disponível em: < http://www.nucleus.feituverava.com.br/index.php/nucleus/article/view/3008/2645>.

BRACCINI, A. L.; MARIUCCI, G. E. G.; SUZUKAWA, A. K.; LIMA, L. H. S.; PICCININ, G. G. Co-inoculação e modos de aplicação de bradyrhizobium japonicum e azospirillum brasilense e adubação nitrogenada na nodulação das plantas e rendimento da cultura da soja. Scientia Agraria Paranaensis. v. 15, n. 1, p. 27-35, 2016. DOI: 10.18188/1983-1471. Disponível em: <http://dx.doi.org/10.1818/sap.v15i1.10565>.

CONAB. Série histórica das safras, $2018 . \quad$ Disponível em:<https://www.conab.gov.br/info-agro/safras/serie-historica-das-safras?start=20>. Acesso em: 10 de julho de 2018.

DOMINGOS, C. S.; LIMA, L. H. S.; BRACCINI, A. L. Nutrição mineral e ferramentas para o manejo da adubação na cultura da soja. Scientia Agraria Paranaensis. v.14, n.3, p.132-140, 2015. DOI: 10.18188/1983-1471. Disponível em: <http://dx.doi.org/10.1818/sap.v14i3.12218>.

EMBRAPA,

Clima.

Disponível

em:< http://www.cnpf.embrapa.br/pesquisa/efb/clima.htm >. Acesso em: 10 de julho de 2018.

EMBRAPA. Tecnologia de produção de soja - Região Central do Brasil 2014. Disponível em: <https://www.embrapa.br/busca-de-publicacoes//publicacao/975595/tecnologias-de-producao-de-soja---regiao-central-do-brasil2014>.

FERREIRA, D. F. 2010. Sistema de análise SISVAR - de variância. Versão 5.3. Lavras-MG: UFLA.

FUNCEME - Fundação Cearense de Meteorologia e Recursos Hídricos. 2012. Levantamento de reconhecimento de média intensidade dos solos da Mesorregião do Sul Cearense / Fundação Cearense de Meteorologia e Recursos Hídricos. Fortaleza. Disponível em: < $\mathrm{ftp}: / / \mathrm{ftp}$.funceme.br/Meio_ambiente/ZACE/tmp/folha/folhas.6.pdf>. Acesso em: $10 \mathrm{de}$ julho de 2018.

JÚLIO, O. L. L.; ASCARI, J. P.; MENDES, I. R. N.; SANTOS, E. S.; NIED, A. H. Formas de adubação potássica e produtividade da cultura da soja. Revista Agrarian. v.9, n.32, p. 149-155, 2016. Disponivel em: http://ojs.ufgd.edu.br/index.php/agrarian/article/view/4004/3648.

KAWAVATA, C. K. H.; FOIS, D. A. F.; COPPO, J. C.; ALVES NETO, A. Influência de doses e de duas fontes de potássio no sistema radicular do milho e na condutividade elétrica no solo. Investigação Agrária. v. 19, n. 1, p. 28-34, 2017. Disponível em: <http://www.agr.una.py/revista/index.php/ria/article/view/394>. 
KORBER, A. H. C.; PINTO, L. P.; PIVETTA, L. A.; ALBRECHT, L. P.; FRIGO, K. D. A. Adubação nitrogenada e potássica em soja sob sistemas de semeadura. Revista de Agricultura Neotropical. v. 4, n.4, p.38-45, 2017. Disponível em: < http://periodicosonline.uems.br/index.php/agrineo/article/view/1653/1726> .

LEAL, A. J. F.; VALDERRAMA, M.; KANEKO, F. H.; LEAL, U. A. S.; PERIN, A.; LUCHESE, K. U. O. Produtividade da soja de acordo com diferentes doses de cloreto de potássio revestido ou não com polímeros. Global Science and Technology. v.08, n.01, p.19-30, 2015. Disponível em: < https://rv.ifgoiano.edu.br/periodicos/index.php/gst/article/view/658/441 > .

LEITE, R. C.; CARNEIRO, J. S. S.; FREITAS, G. A.; CASALI, M. E.; SILVA, R. R. Adubação fosfatada na soja durante três safras consecutivas na nova fronteira agrícola brasileira. Scientia Agraria. v. 18, n. 4, p. 28-35, 2017. Disponível em: < http://dx.doi.org/10.5380/rsa.v18i4.50310>

MANTOVANI, A.; RIBEIRO, F. J.; VEIGA, M.; ZILIO, M.; FELICIO, T. P. Métodos de aplicação de potássio na soja em nitossolo vermelho. Unoesc \& Ciência. v.8, n.2, p. 169-176, $2017 . \quad$ Disponível em: <http://editora.unoesc.edu.br/index.php/acbs/article/view/12662/pdf> .

OLIBONE, D.; CALONEGO, J.C.; PAVINATO, P.S; ROSOLEM, C.A. Crescimento inicial da soja sob efeito de resíduos de sorgo. Planta Daninha. v. 24, n. 2, p. 255261, 2006. Disponível em: <http://dx.doi.org/10.1590/S0100-83582006000200007>.

PAZUCH, A.; CIESCA, D. F.; JUNKES, E. S.; KLEIN, C.; BERWANGER, A. L. Estádios de aplicação da adubação potássica e viabilidade economica na cultura da soja. Anuário Pesquisa e Extensão Unoesc São Miguel do Oeste. v.2, 2017. Disponível em: https://editora.unoesc.edu.br/index.php/apeusmo/article/view/15389/8311>.

PEREIRA, C. S.; FREITAS, A. A.; CHAPLA, M. V.; LANGE, A. Doses de potássio com a presença de enxofre na cultura da soja. Global Science and Technology. v.09, n.01, p.22-32, 2016. Disponível em: < https://rv.ifgoiano.edu.br/periodicos/index.php/gst/article/view/784/492>.

PETTER, F. A.; ALVES, A. U.; SILVA, J. A.; CARDOSO, E. A.; ALIXANDRE, T. F.; ALMEIDA, F. A.; PACHECO, L. P. Produtividade e qualidade de sementes de soja em função de doses e épocas de aplicação de potássio. Semina: Ciências Agrárias. v.35, n.1, p.89-100, 2014. DOI: 10.5433/1679-0359. Disponível em: < http://www.uel.br/revistas/uel/index.php/semagrarias/article/view/11656/14053> .

PIMENTEL GOMES, F. Curso de estatística experimental. 15. Ed. Piracicaba, ESALQ. P.451, 2009.

RODRIGUES, J. C.; VILAR, C. C.; VILAR, F. C. M.; OLIVEIRA NETO, A. M.; BOTTEGA, E. L. Levantamento da utilização das recomendações técnicas quanto a amostragem de solo, calagem e uso de fertilizantes minerais no cultivo da soja, no município de Mato Rico-PR. Campo Digit@I. v. 10, n. 1, p. 18-30, 2015. Disponível 
em:

http://revista.grupointegrado.br/revista/index.php/campodigital/article/view/1756/690 .

TAVARES, L C.; TUNES, L. M.; BRUNES, A. P.; FONSECA, D. A. R.; RUFINO, C. A.; ALBUQUERQUE BARROS, A. C. S. A. Potássio via recobrimento de sementes de soja: efeitos na qualidade fisiológica e no rendimento. Ciência Rural. v.43, n.7, p.1196-1202, 2013.

Disponível

em:

http://www.redalyc.org/articulo.oa?id=33127846009 .

TRIGOLO, A. L. M.; QUAREZEMIN, M. A. K.; GERMANO, M. G.; CASTRO, C.; OLIVEIRA JUNIOR, A. Contribuição do potássio não trocável para a produtividade de soja e milho safrinha. EMBRAPA. p.35-43, 2015.

VENTUROSO, L. R.; BERGAMIN, A. C.; VALADÃO JÚNIOR, D. D.; LIMA, W. A.; OLIVEIRA, W. B.; SCHLINDWEIN, L. A.; CARON, B. O.; SCHMIDT, D. Avaliação de duas cultivares de soja sob diferentes doses de potássio, no município de Rolim de Moura, RO. Agrarian. v.2, n.4, p.17-29, 2009. Disponível em: < http://ojs.ufgd.edu.br/index.php/agrarian/article/view/543/381> . 